\title{
Latitudinal variability of the quasi-16-day wave in the middle atmosphere over Brazilian stations
}

\author{
Amitava Guharay ${ }^{1}$, Paulo Prado Batista ${ }^{2}$, Barclay Robert Clemesha ${ }^{2}$, Ricardo Arlen Buriti ${ }^{3}$, and \\ Nelson Jorge Schuch ${ }^{4}$ \\ ${ }^{1}$ Space and Atmospheric Sciences Division, Physical Research Laboratory, Ahmedabad, GJ, India \\ ${ }^{2}$ Aeronomy Division, National Institute for Space Research, INPE, São José dos Campos, SP, Brazil \\ ${ }^{3}$ Federal University of Campina Grande, Campina Grande, PB, Brazil \\ ${ }^{4}$ Southern Regional Space Research Center, Santa Maria, RS, Brazil \\ Correspondence to: Amitava Guharay (guharay@prl.res.in)
}

Received: 19 October 2015 - Revised: 13 January 2016 - Accepted: 18 March 2016 - Published: 12 April 2016

\begin{abstract}
A comparative study of the quasi-16-day wave (QSDW) in the middle atmosphere using meteor radar observations and reanalysis data from three Brazilian stations, Sao Joao do Cariri $\left(7.4^{\circ} \mathrm{S}, 36.5^{\circ} \mathrm{W}\right)(\mathrm{CA})$, Cachoeira Paulista $\left(22.7^{\circ} \mathrm{S}, 45^{\circ} \mathrm{W}\right)(\mathrm{CP})$, and Santa Maria $\left(29.7^{\circ} \mathrm{S}, 53.7^{\circ} \mathrm{W}\right)$ (SM) has been carried out in the year 2005 to delineate its latitudinal variability characteristics. The broad spectral behavior around 16-day periodicity may indicate multiple modes of the concerned wave component. The wave amplitude shows a number of peaks over the year with the largest one in summer and winter in the case of mesosphere-lower thermosphere (MLT) and stratosphere, respectively. A potential coupling of the concerned wave with other short period planetary waves, especially at $\mathrm{CA}$ and $\mathrm{CP}$ is evinced. Although zonal propagation exhibits both eastward as well as westward waves there is a general preference of eastward waves at mid-latitude and westward waves at tropical latitudes. The prevailing westerly background wind in the middle atmosphere is conceived to favor the wave filtering of westward propagating Rossby waves at lower latitude.
\end{abstract}

Keywords. Meteorology and atmospheric dynamics (middle atmosphere dynamics; waves and tides) - space plasma physics (wave-wave interactions)

\section{Introduction}

The planetary waves (period $\sim 2-20$ days) are an important coupling agent of various atmospheric layers starting from troposphere up to mesosphere and thermosphere. The dy- namics of the mesosphere and lower thermosphere (MLT) is mainly controlled by the atmospheric waves of various scales among which planetary waves play a pivotal role to deposit energy and momentum to the mean flow. Past studies showed interaction between waves and mean flow could cause significant change in the ambient background condition as well as the behavior of the propagating waves. It is now understood that a large number of planetary waves existing in the MLT are not excited in situ, but propagate from the troposphere and stratosphere after generation. In fact, variations in the middle atmospheric temperature, wind fields, and chemical species concentration are significantly governed by these waves. The stationary planetary waves are generated in the troposphere due to orography and diabatic heating. The traveling planetary waves are excited by irregular thermal or mechanical forcing in the lower atmosphere and instabilities in the middle atmosphere. Latitudinal and vertical coupling of the lower and middle atmosphere during sudden stratospheric warming is found to be caused by strong planetary wave field (Hoffmann et al., 2007; Guharay and Sekar, 2012; Guharay et al., 2014).

A prominent category of the planetary waves consists of normal modes of periods $2,5,10$, and 16 days which could be considered as free or resonant atmospheric modes (Salby, 1981). The 16-day wave is conceived to be a manifestation of the gravest symmetric westward propagating Rossby normal mode with zonal wavenumber 1 (Salby, 1981). The wave was first reported observationally in the MLT by Kingsley et al. (1978) with the help of meteor wind measurements from Sheffield $\left(53^{\circ} \mathrm{N}, 2^{\circ} \mathrm{W}\right)$. The period of the wave varies in the 
range 12-20 days. The amplitude of the wave can reach as much as $15 \mathrm{~m} \mathrm{~s}^{-1}$ in winter and in summer it could attain a value close to $10 \mathrm{~m} \mathrm{~s}^{-1}$ (Mitchell et al., 1999; Day and Mitchell, 2010). Considerable amplitude of the wave in temperature and wind over various locations of the globe was reported by the earlier observations and modeling studies in the MLT and stratosphere (Forbes et al., 1995; Luo et al., 2002; Day and Mitchell, 2010; McDonald et al., 2011).

Seasonal variability of the quasi-16-day wave (QSDW) activity was reported by a handful of past investigations (Mitchell et al., 1999; Luo et al., 2002; Day and Mitchell, 2010). Forbes et al. (1995) simulated the wave behavior from the ground to $140 \mathrm{~km}$ and demonstrated direct penetration of the waves from the lower atmosphere as well as a plausible ducting channel through which the wave propagates from the winter to summer hemisphere. Using 4-year meteor radar observations from a mid-latitude station in the Northern Hemisphere, Mitchell et al. (1999) found amplitude maximum around winter-spring and a secondary maximum with comparatively smaller value around summer-fall intervals. Later, using a network of five MF radars distributed from the high to equatorial latitudes in the Northern Hemisphere, Luo et al. (2002) concluded that the wave phenomenon was strong in winter. Using meteor radar measurements over two sites located near both poles, Day and Mitchell (2010) found stronger wave activity in winter as compared to the summer. In contrast to such an occurrence, Williams and Avery (1992) reported stronger wave activity in summer mesopause using observations from a mid-latitude station, although they found significant QSDW amplitude in winter in the stratosphere. With the help of satellite-based Microwave Limb Sounder (MLS) derived temperature observations, McDonald et al. (2011) showed considerable seasonal as well as inter-annual variability of the wave consisting of eastward and westward propagating zonal wavenumber 1 and 2 components. They reported that both eastward and westward components are large in the Northern Hemisphere, whereas eastward components predominate in the Southern Hemisphere.

The phase of the quasi-biennial oscillation (QBO) is believed to cause a wave filtering by supporting the wave propagation in the westerly phase and obstructing the same in easterly phase (Espy et al., 1997; Jacobi et al., 1998). However, a few other investigators concluded that the QBO influence on the QSDW was not a permanent feature rather it was intermittent (Mitchell et al., 1999; Day et al., 2011).

Although a number of investigations carried out observationally and theoretically over various locations of the globe, our understanding of these prominent atmospheric normal modes is not complete, especially its features in the Southern Hemisphere where planetary waves are generally weaker as compared to the Northern Hemisphere (Volland, 1988). A previous study by Lima et al. (2006) from Cachoeira Paulista $\left(22.7^{\circ} \mathrm{S}, 45^{\circ} \mathrm{W}\right)$ illustrated the inter-annual variability of the QSDW in the MLT with more than 5 years of horizontal wind data. The most recent studies by Guharay et al. (2015a, b) from the same location reported significant modulation of the diurnal tide and quasi-2-day wave amplitude in the period of $\sim 16$ days implying an important role of QSDW in controlling shorter period waves by modifying the mean background wind. In the present paper an attempt has been made to look into the latitudinal variability of the wave along with zonal propagation characteristics and its coupling with other planetary waves with shorter periodicities using meteor radar and reanalysis data from three Brazilian stations: Sao Joao do Cariri (CA, $7.4^{\circ} \mathrm{S}, 36.5^{\circ} \mathrm{W}$ ), Cachoeira Paulista (CP), and Santa Maria (SM, 29.7 $\left.\mathrm{S}, 53.7^{\circ} \mathrm{W}\right)$, which have remained untouched so far.

\section{Database and analysis}

\subsection{Meteor radar observations}

The meteor radar systems used for the present study located at Cariri (CA), Cachoeira Paulista (CP), and Santa Maria (SM) are basically SKiYMET radars. These identical radars operate at $35.24 \mathrm{MHz}$ with a pulse width of $13 \mu \mathrm{s}$, peak power of $12 \mathrm{~kW}$, and pulse repetition frequency of $2 \mathrm{kHz}$. The signal transmitter consists of a three-element Yagi antenna and for receiving the backscattered signal, five phase coherent two-element antennas aligned along two orthogonal baselines with one antenna at the center common to both are utilized. Daily received echoes (maximum and minimum approximately 5000 and 720, respectively) are analyzed to estimate range, angular position, radial velocity etc. Details of the algorithm can be found in the available literature (Hocking et al., 2001). Present research work utilizes the zonal and meridional wind data of temporal and spatial resolutions of $1 \mathrm{~h}$ and $3 \mathrm{~km}$, respectively in the MLT $(81-99 \mathrm{~km})$ for the year 2005 when data reception for all the three stations are found to be very regular. The uncertainty in the measured wind velocity is less than $20 \%$.

\subsection{ERA-Interim database}

ERA-Interim database is provided by the European Centre for Medium-range Weather Forecasts (ECMWF). The daily zonal and meridional wind data available at latitudelongitude grid of $0.25^{\circ} \times 0.25^{\circ}$ at the pressure level $10 \mathrm{hPa}$ $(\sim 31 \mathrm{~km})$ for the year 2005 at the three stations are used for the present study.

Standard wavelet technique is utilized to identify the dominant periodicities in the MLT and stratospheric wind data. To calculate the daily variance of the QSDW the data are subjected to a band pass filter of cut off periods of 12 and 20 days. The variance is derived using a 41-day window which is shifted by 1 day progressively. Similarly, the daily amplitude of the wave is estimated by least square fit to the unfiltered data considering a 41-day window and a progressive shift of the same by 1 day. The fit is carried out by con- 
straining the period within the limit of 12-20 days. The daily eastward and westward 16-day wave amplitudes for various wave numbers are estimated in the ERA-Interim horizontal winds by applying two-dimensional fast Fourier transform (FFT) on a window of 32 days with a progressive shift of 1 day.

To find out possible coupling and/or nonlinear interactions of the QSDW with shorter period planetary waves, bispectral analysis has been carried out. It can be mentioned that due to nonlinear interaction between two primary waves, two secondary waves with frequencies equal to sum and difference of the primary frequencies will be generated. The bispectral analysis is a useful tool to determine quadratic phase coupling in a triplet formed by any three of the four wave components (two primary and two secondary waves). A non-zero value in the bispectrum is expected in case of resonance condition, i.e., when $f_{3}=f_{1}+f_{2}$ and $\varphi_{3}=\varphi_{1}+\varphi_{2}$, here $f$ denotes frequency and $\varphi$ denotes phase. The bispectrum can be expressed as an average of the complex product of three Fourier components, where one frequency is the sum of the other two. According to Kim and Powers (1979), bispectrum in the two-dimensional domain of frequencies $f_{1}, f_{2}$ can be expressed as

$\hat{B}\left(f_{1}, f_{2}\right)=\frac{1}{m} \sum_{i=1}^{m} F_{i}\left(f_{1}\right) F_{i}\left(f_{2}\right) F_{i}^{*}\left(f_{1}+f_{2}\right)$.

Here the original time series is split into a number of segments with each segment containing $n$ points. $F(f)$ denotes the Fourier transform of the time series wind corresponding to the frequency $f$ within a particular data segment, ${ }^{*}$ denotes complex conjugate. $\mathrm{m}$ is the number of data segments for each of which the Fourier transform is estimated. In the present case $m=50$. The segment width is chosen to be 120 days ( $n=2880$ points) which is progressively shifted by 5 days ( 120 points) ensuring sufficient overlap $(96 \%)$ between any two adjacent segments. The segment width (120 days) is chosen to incorporate sufficient planetary wave components near the highest period (for the present case it is chosen to be 30 days) wherein oscillation components are sparse.

\section{Results}

The wavelet power spectra at $90 \mathrm{~km}$ in the zonal and meridional wind are shown in Fig. 1 to identify the planetary wave components existing during the observational span. The seasons are represented by the abbreviations as LS (late summer), F (fall), W (winter), S (spring), ES (early summer) and divided by bold vertical lines in the present and all the following plots. The solid curves in the plots represent $95 \%$ confidence level. Wave periodicities are found to be more prominent in the zonal wind as compared to the meridional wind for all three stations. Higher periods are more dominant as compared to their low period counterparts. If we consider

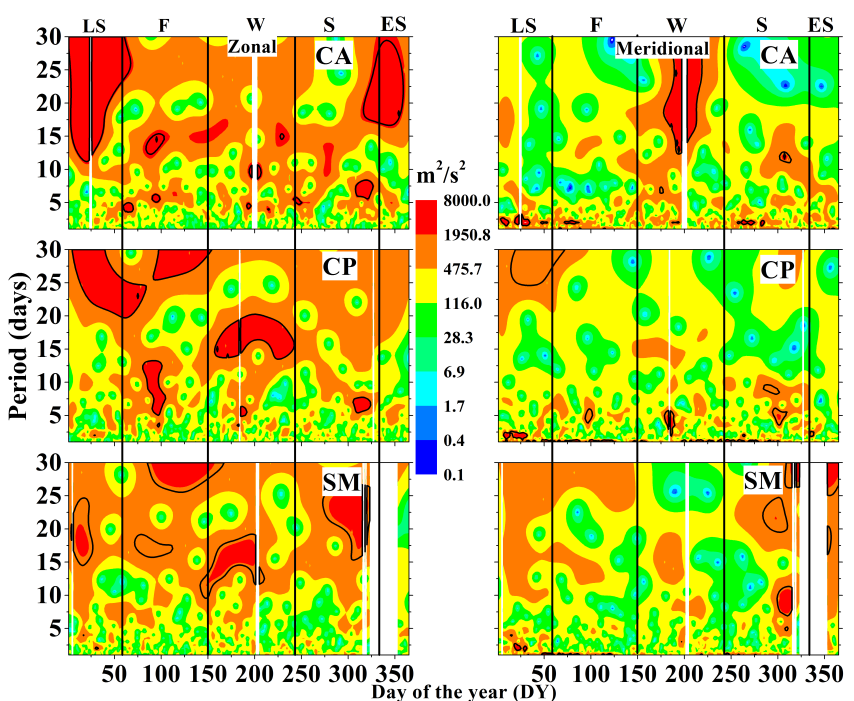

Figure 1. Wavelet power spectra estimated at $90 \mathrm{~km}$ using meteor radar zonal and meridional winds at $\mathrm{CA}, \mathrm{CP}$, and SM. The bold curves represent $95 \%$ confidence level. The seasons, i.e., late summer (LS), fall (F), winter (W), spring (S), early summer (ES) are separated by vertical lines.

the period range associated with the QSDW, i.e., 12-20 days, we find it to be strongest in summer in the zonal wind and in winter in the case of meridional wind at Cariri. At Cachoeira Paulista the wave is observed to be strong in winter in the zonal component, whereas it is not evident in the meridional wind. At Santa Maria the wave is intermittently visible over various spans of the year in the zonal wind and it is prominent in the meridional wind in late spring and early summer. Therefore evident from the plots is significant latitudinal variability of the wave prevalence as well as difference in wave activity between the zonal and meridional components implying wave polarization.

Figure 2 shows the variance in the zonal and meridional winds associated with the QSDW in the MLT. The value of the variance is significantly higher in the zonal component as compared to the meridional wind. Another notable feature is that the wave variance is comparable for CA and SM, whereas it is considerably lower in the case of CP. In general, the variance is largest around winter for all the three sites although zonal wind variance at CA shows maximum in late summer. The maximum variance is found to be highly localized. Secondary maxima are also evident during spring and summer at certain altitude bins.

Altitudinal mean of daily amplitude of the QSDW is shown in Fig. 3. In general, the amplitude exhibits a number of broad maxima during various times of the year with considerably higher values in the case of zonal wind at CA and SM. On the other hand an additional maximum is visible in fall at CP and in spring at SM in the zonal wind. The highest amplitude among all the three sites is found at CA during late summer. The summer maxima at CA and SM are larger 


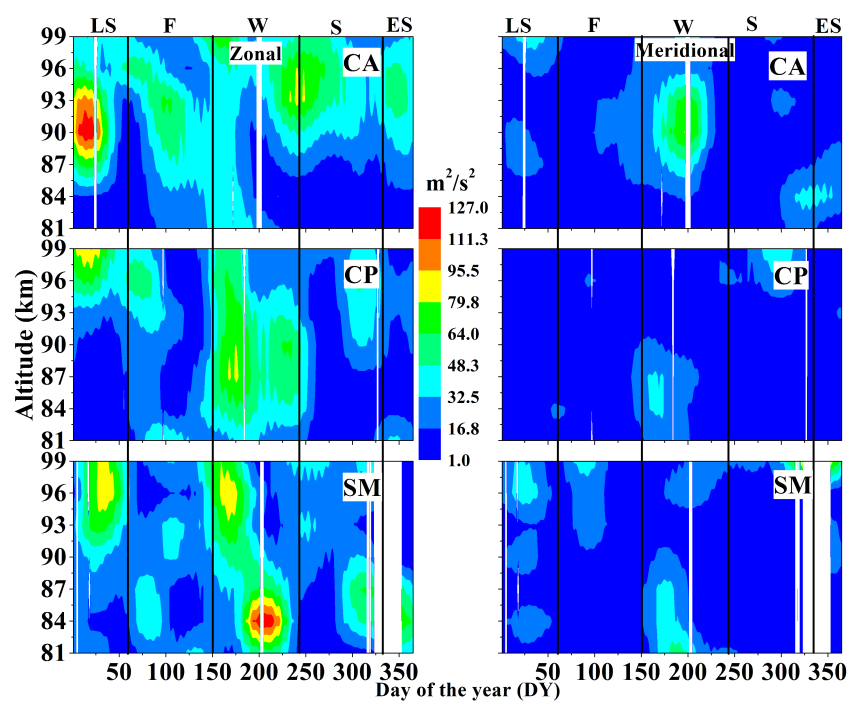

Figure 2. QSDW variance in the MLT estimated from the zonal and meridional winds for the three locations.

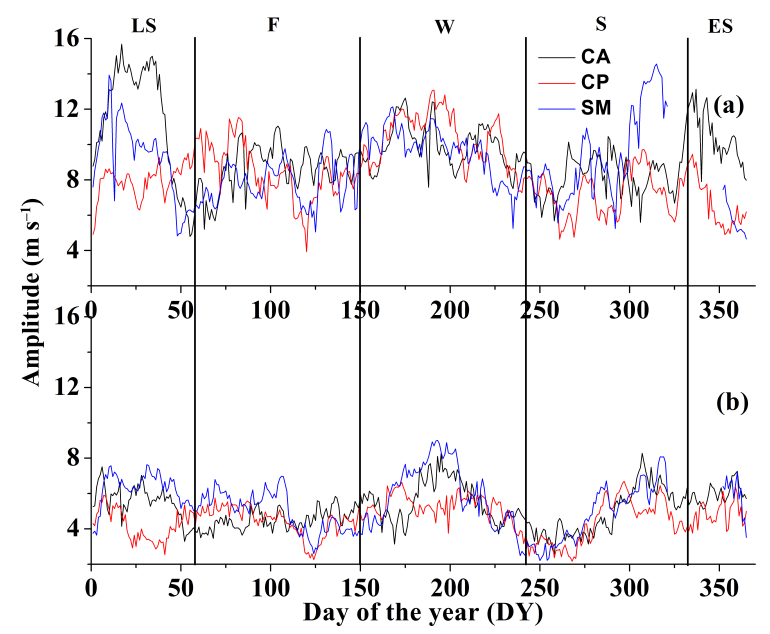

Figure 3. Vertical averaged amplitude of the QSDW in the MLT in the (a) zonal and (b) meridional winds for 3 stations.

than the winter ones in the zonal wind and winter maxima are found to be larger compared to the summer peaks in the meridional wind. However, it should be mentioned that the mean wave amplitudes are significantly higher in the zonal wind compared to the meridional wind.

The stratospheric planetary wave activities over the observational sites illustrated by wavelet profiles of ECMWF zonal and meridional wind at $10 \mathrm{hPa}$ level $(\sim 31 \mathrm{~km})$ are shown in Fig. 4. The bold lines in the plot denote $95 \%$ confidence level. The wave signatures of a period of less than 5 days are found to be very weak unlike the MLT. In general longer waves (period $\sim 10-30$ days) are strong in the winter which show relative enhancement of various components in this interval. Wave activity (period $\sim 10-30$ days) is also found to be significant during spring and early summer, al-

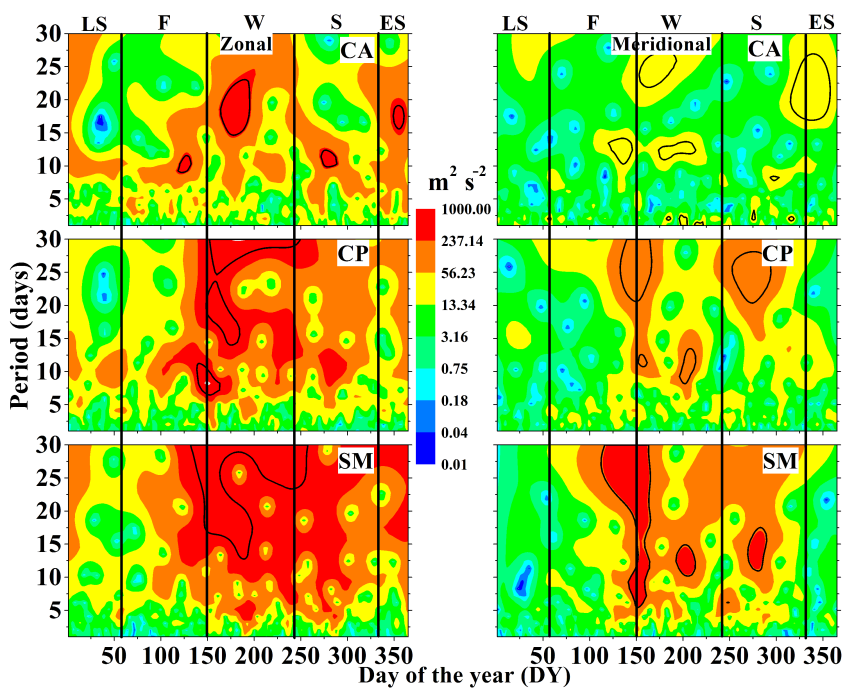

Figure 4. Wavelet power spectra estimated at $10 \mathrm{hPa}$ pressure level using ECMWF zonal and meridional winds at CA, CP, and SM. The bold curves represent $95 \%$ confidence level.

though this feature is not common to all cases. Similar to the MLT the zonal wind power is much higher as compared to the meridional one indicating potential wave dynamical coupling of the stratosphere and MLT through the QSDW.

The variation of the stratospheric winds with respect to longitude at $10 \mathrm{hPa}$ level filtered by a band pass filter of cutoff periods of 12 and 20 days corresponding to the latitudes of the present observational stations are shown in Fig. 5. The horizontal dashed lines denote the longitudes of the sites $7.5^{\circ} \mathrm{S}(\sim \mathrm{CA}), 22.75^{\circ} \mathrm{S}(\sim \mathrm{CP})$, and $29.75^{\circ} \mathrm{S}(\sim \mathrm{SM})$. The wave amplitude is found to increase with the latitude. The profiles exhibit wave packets of large amplitude over certain temporal intervals especially in the zonal wind in winterspring time. The direction of wave propagation is shown by arrows. It can be noted that the wave packets propagate westward at CA. At CP the wave packets are found to propagate both eastward and westward. On the other hand, the wave packets are observed to propagate only along eastward direction at SM.

The amplitudes of the eastward and westward propagating 16-day wave estimated from the ECMWF zonal wind for the zonal wave numbers $1,2,3$ at $10 \mathrm{hPa}$ level for the three stations are shown in Fig. 6. The amplitude is high in winterearly summer interval and the maximum amplitude peak is observed in winter. In general, wave number 1 component is much higher in amplitude as compared to other components at CA most of the time. At CP wave number 2 amplitude is significantly large and comparable to the wave number 1 most of the times unlike CA. In addition to the wave number 1 and 2 components the eastward propagating wave number 3 component is found to be significant in winter although it is much smaller compared to the other components. Among all the stations the amplitude is found to be maximum at SM 


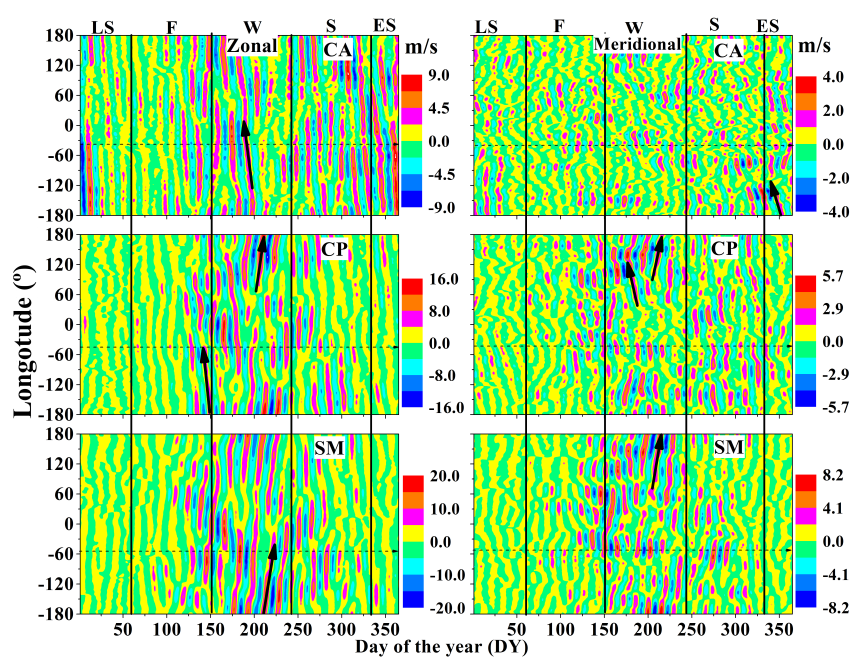

Figure 5. Longitudinal and temporal variation of the filtered ECMWF zonal and meridional winds in the period band 12-20 days at $10 \mathrm{hPa}$ pressure level for the locations $7.5^{\circ} \mathrm{S}(\sim \mathrm{CA}), 22.75^{\circ} \mathrm{S}$ $(\sim \mathrm{CP})$, and $29.75^{\circ} \mathrm{S}(\sim \mathrm{SM})$. The arrows in the plots show the direction of the propagation of the waves.

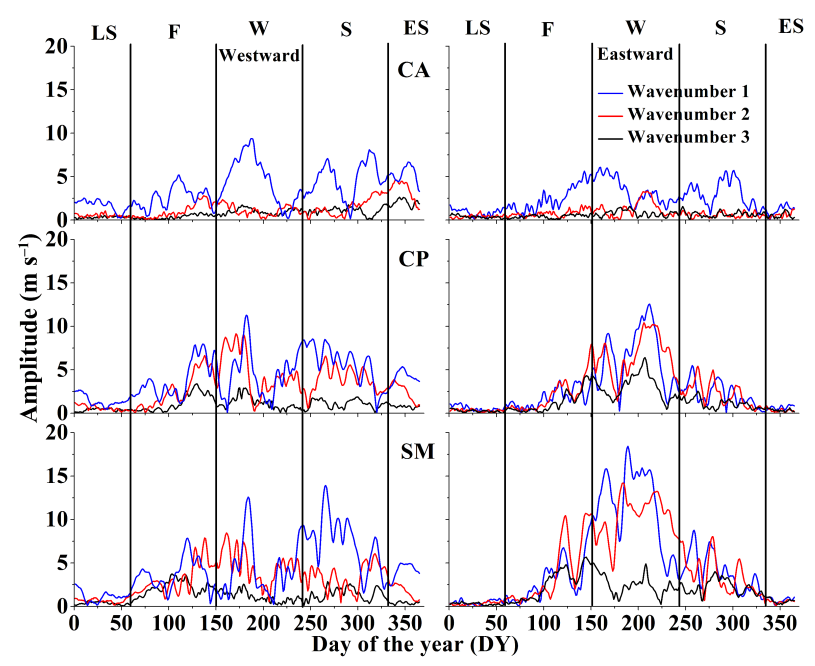

Figure 6. Amplitude of the eastward and westward propagating 16day wave at $10 \mathrm{hPa}$ pressure level at three stations corresponding to the zonal wave numbers 1,2, and 3 derived from the ECMWF zonal wind.

for the eastward wave number 1 and 2 components. Therefore from the results it can be noted that the zonal wave number 1 is the strongest component at CA, whereas both wave number 1 and 2 components are dominant at $\mathrm{CP}$ and $\mathrm{SM}$. At $\mathrm{CA}$ westward components are predominate, at CP both eastward and westward components are significant, and at SM eastward components are found to be dominant which are consistent with the filter profiles.

Figure 7 shows the amplitude of the 16-day wave for various zonal wave numbers derived from the ECMWF merid-

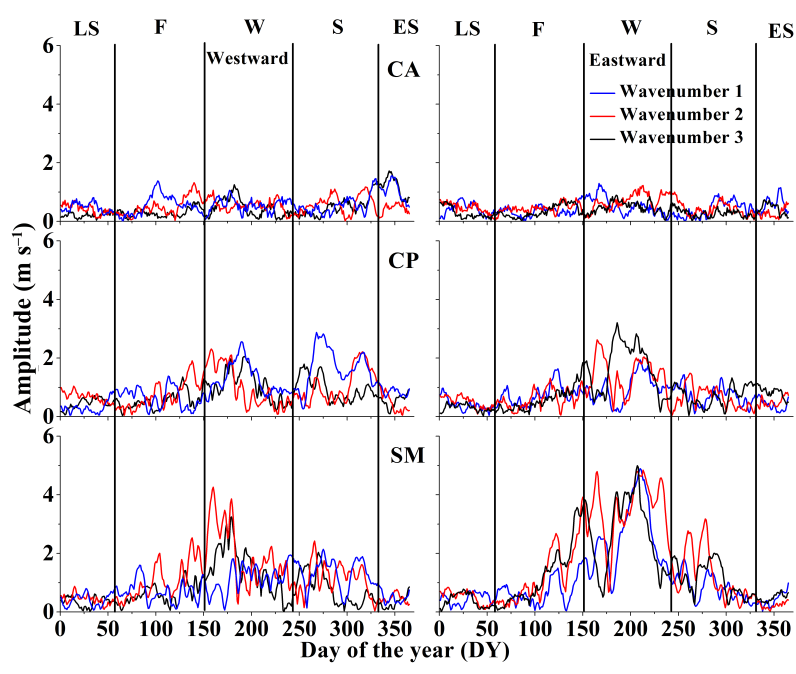

Figure 7. Same as Fig. 6, but here it is for the meridional wind.

ional wind. Evident from the plot is much lower wave amplitude in the meridional wind compared to the zonal wind derived ones which is consistent with the previous analyses results depicted before. At CA the wave amplitudes are comparable among various wave numbers for both eastward and westward components. The wave number 3 component in the meridional wind is found to be comparable with the other two components at $\mathrm{CP}$ and SM unlike zonal wind. A common feature between the zonal and meridional components is the largest eastward amplitude at SM.

Figure 8 plots the bispectra at $90 \mathrm{~km}$ for the three observational sites using meteor winds. The abscissa is ranged between 12 and 20 days for considering QSDW and the ordinate is shown between 2 and 12 days to illustrate lower period planetary waves. It should be mentioned that the absolute values of the bispectra do not bear any significance, rather the relative value is the one of importance. The zonal spectrum at CA shows possible interactions of the QSDW with 4.5-, 6- and 9-day waves. Apart from the longer periods the meridional spectrum at CA shows coupling with lower periodicities $(<3.5$ days). At $\mathrm{CP}$ the wave with period $>8$ days is found to be coupled with the QSDW. In the meridional spectrum wave periods $\sim 3.5-5$ days are found to be involved in the interactions. The estimated bispectra at $10 \mathrm{hPa}$ using ECMWF zonal and meridional winds are shown in Fig. 9. The periodicities found to be involved in the interactions with the QSDW are > 8 days at all sites and both components except the meridional spectrum at $\mathrm{CA}$ which shows interactions at a period $<3.5$ days. At SM interaction features are visible in the stratosphere although it is insignificant in the MLT.

Background zonal wind is an important factor to control the propagation of the atmospheric waves. The daily variation of the background zonal wind in the MLT and troposphere-stratosphere (TS) is shown in Fig. 10. Evident from the plot is the increase of magnitude of the wind with 


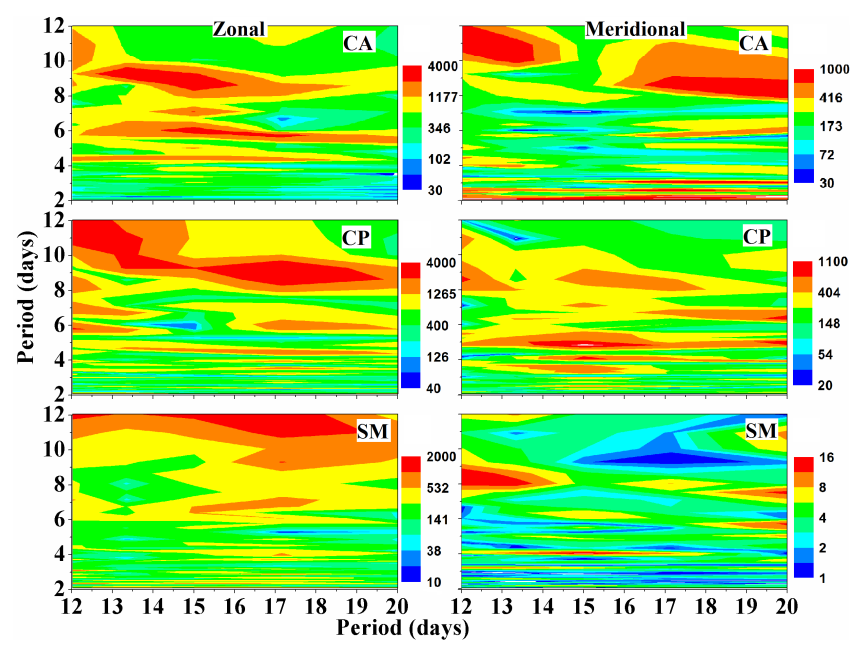

Figure 8. Bispectra in terms of normalized power calculated from the meteor zonal and meridional winds at $90 \mathrm{~km}$ for three stations. Please note that the abscissa is ranged within 12-20 days period to express QSDW and the ordinate is scaled within the range 212 days to show shorter periods.

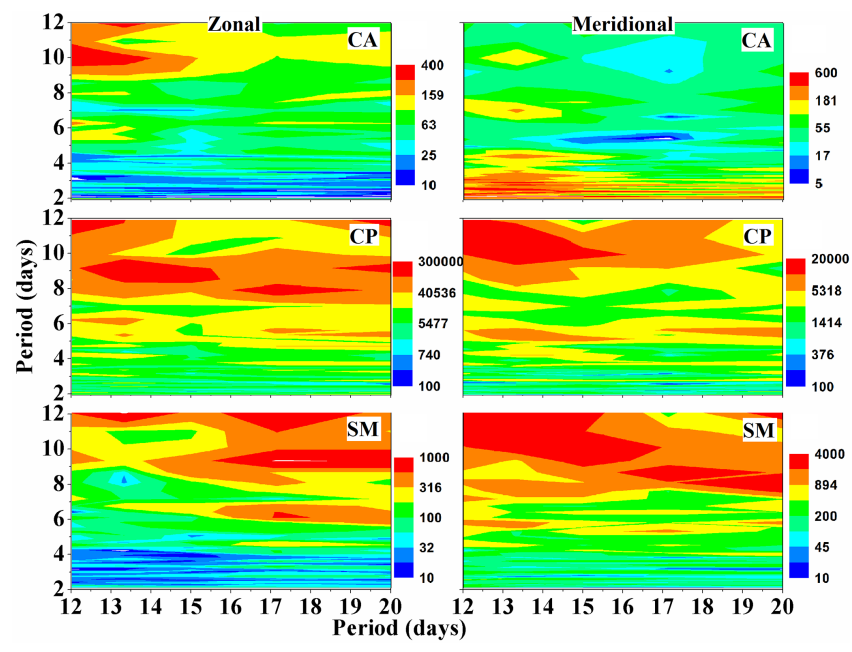

Figure 9. Same as Fig. 8, but it is at $10 \mathrm{hPa}$ pressure level.

the latitude. Also it can be noted that the westerly wind strengthens with the latitude. Common feature from the plot is the strongest westerly wind at low-MLT during winter at all the sites. A secondary peak of westerly wind is found at mid- and high-MLT in early summer at CP and SM. Significantly strong westerly wind during winter at low-MLT may be considered to be responsible for facilitating wave activity in the MLT since westerly wind supports the westward propagating Rossby modes by wave filtering. The daily variability is notably smaller in the TS as compared to the MLT. Strong westerly and easterly winds are found at upper stratosphere (> $40 \mathrm{~km}$ ) during May-June and November-February intervals, respectively which shows latitudinal increase in magnitude. The altitude region between 2 and $20 \mathrm{~km}$ exhibits mod-

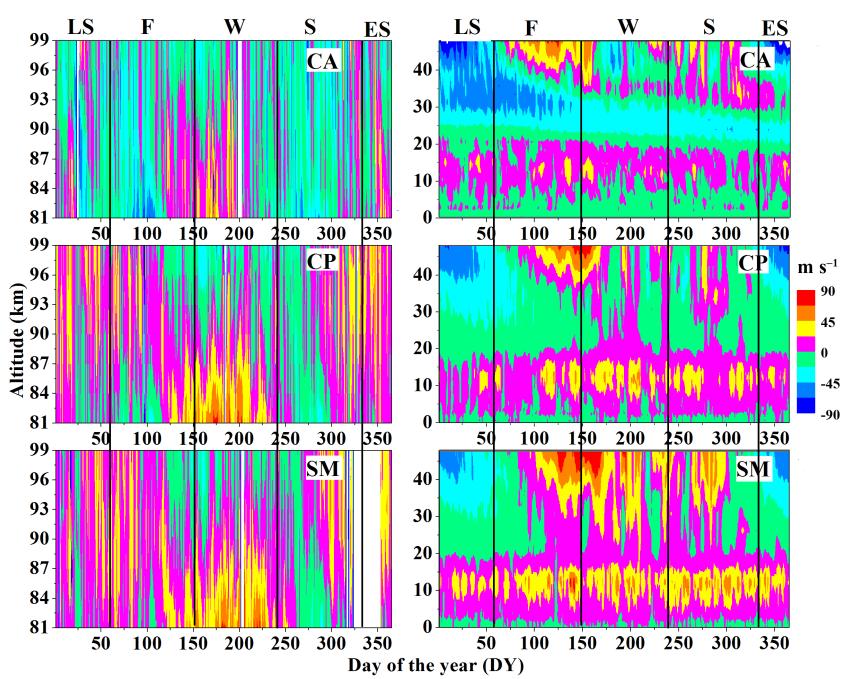

Figure 10. Temporal variability of the zonal wind in the MLT and TS at three sites.

erate westerly wind throughout the year. The moderate easterly wind is very consistent throughout the year around 20$30 \mathrm{~km}$ at CA.

\section{Discussion}

The present study from three southern hemispheric Brazilian stations depicts the latitudinal variability signature of the QSDW. The features of the wave in the Southern Hemisphere are studied inadequately so far and hence bear significance in the light of the existing literatures and present understanding in this regard.

Charney and Drazin (1961) derived a set of equations which describe the propagation of the stationary planetary waves. They concluded that the infinite region of negative refractive index squared caused total reflection of the waves, while a finite region of negative refractive index squared between two regions of positive refractive index squared favored partial reflection of the waves. These inferences could also be applied for traveling planetary waves by assuming nonzero phase velocity of the waves. The refractive index is a quantity governed by the zonal wind. According to the Charney and Drazin (1961) theorem a planetary wave can propagate vertically upward if it satisfies the condition, $0<u-c<U_{\mathrm{c}}$, where $u$ is the zonal wind speed, $c$ is the zonal phase velocity of the wave and $U_{\mathrm{c}}$ is the critical Rossby speed. High wave activity in the stratosphere and MLT in winter in the presence of strong westerly wind as seen in the present case indicates significant consistency with the Charney-Drazin theory.

It can be noted that in addition to the westward planetary wave modes, considerable eastward propagating waves are observed at all the stations in the stratosphere which is found to be significant at SM (highest latitude among all sta- 
tions) especially in winter-spring interval. Therefore strong eastward components of the QSDW at a higher latitude in winter-spring as noted in the present study are not consistent with the theory discussed above. There could be two plausible mechanisms for enhancement of the eastward waves, i.e., (i) propagation through ducting channel from the other hemisphere and (ii) excitation due to barotropic and/or baroclinic instability driven by a westerly jet. If we consider ducting as being the responsible mechanism then similar eastward wave enhancement at lower latitude is also expected which is not found in the present scenario. Therefore we surmise that the ducting mechanism is unlikely to cause eastward propagating wave amplification at higher latitude in the winter-spring interval in the stratosphere, in this case the barotropic and/or baroclinic instability may excite the waves in the presence of the westerly wind. However, ephemeral westward peaks especially in winter-spring period over all the stations could be conceived as a result of ducting favored propagation from the Northern Hemisphere. Nevertheless, with limited observations it is not possible to affirm exact mechanism/s responsible for wave excitation, so we attempted to indicate some probable factors and hence further investigations in this direction are still required to gain more insights into the actual underlying processes.

It is already mentioned that the eastward waves are stronger compared to the westward counterparts during the winter-spring interval in the stratosphere at $\mathrm{CP}$ and SM. Actually, in the Northern Hemisphere quasi-stationary planetary waves and westward propagating normal mode Rossby waves are dominant planetary waves. On the other hand, in the Southern Hemisphere, apart from these modes, eastward traveling planetary waves are also found to be significantly strong which are generated due to instability driven by the strong westerly jet (Shiotani et al., 1990). In the Southern Hemisphere constructive interference between the quasistationary wave of zonal wave number 1 and eastward propagating wave of wave number 2 could cause the amplification of the quasi-stationary wave 1 (Shiotani et al., 1990). Such interaction between the eastward wave number 2 and quasi-stationary wave number 1 was also verified by Ushimaru and Tanaka (1992). They found anti-correlation behavior between the aforesaid two waves, indicating a clear relationship of energy and entropy exchange in the interaction. Since the westerly jet becomes stronger with latitude in the present study, the instability also enhances and as a consequence stronger eastward wave amplitude is observed at higher latitudes. It can be mentioned that wintertime strong quasi-stationary planetary wave amplitudes are very likely to overestimate the traveling wave amplitudes as derived in the present study. Therefore observed wintertime amplitude in the stratosphere may not be purely due to traveling planetary waves and it may be a manifestation of combined contributions from quasi-stationary and traveling planetary waves. A previous study from a southern hemispheric midlatitude station, Grahamstown $\left(33.3^{\circ} \mathrm{S}, 26.5^{\circ} \mathrm{W}\right)$, Malinga and Poole (2002) reported strong QSDW activity in winter stratosphere due to a strong westerly jet. Using satellitebased observations, Shepherd and Tsuda (2008) reported a strong eastward 16-day wave coupling with the quasistationary waves of zonal wave number 1 and 2 at Antarctic latitudes.

Using EOS MLS observations, McDonald et al. (2011) reported stronger eastward QSDW of zonal wave numbers, 1 and 2 as compared to the westward components in the Southern Hemisphere which is very similar to the present results. Of late, Lu et al. (2013) studied the characteristics of the eastward propagating waves in the southern hemispheric winter using satellite-based data in the middle atmosphere and reported strong wave activity at higher latitude and sufficiently smaller at lower latitudes due to negative refractive index squared inhibiting the equatorward propagation of the excited waves or in other words there was a confinement of the planetary waves at higher latitude $\left(>50^{\circ} \mathrm{S}\right)$. Increase of eastward wave amplitude with latitude especially for the wave numbers 1 and 2 as found in the present study is consistent with the past findings of Lu et al. (2013).

Although the QSDW is very strong in summer in the MLT it shows largest amplitude in winter in the case of stratosphere. Taking a glance at Fig. 6 one can note that summer time wave amplitudes are larger for westward waves although they are somewhat smaller compared to the eastward counterparts in winter in the stratosphere. The westerly wind in the upper troposphere is supportive for propagation of the westward waves. But easterly wind in the stratosphere during summer may prevent the further propagation of the waves to the mesosphere. Nevertheless the summer time MLT is found to show considerable wave activity. The summer MLT wave activity can be attributed to propagation of the planetary waves from the winter hemisphere through cross-equatorial ducting. In this context it can be noted that the wind in the MLT is mainly westerly and increases with latitude favoring the filtering of the westward waves from the winter hemisphere through ducting channel. Another possibility of the summer QSDW enhancement in the MLT could be through gravity waves. Gravity waves modulated by the QSDW in the lower atmosphere can propagate to mesosphere and imprint the feature of the QSDW as they dissipate there by depositing energy and momentum in the MLT as explained in the previous literature by Williams and Avery (1992). Unfortunately, contribution of the gravity waves is not looked into in the present case due to a lack of high temporal resolution data. Using numerical simulation, Forbes et al. (1995) inferred that inter-hemispheric propagation through ducting channel is diminished by gravity wave stress to some extent. They also indicated the possibility of in situ excitation of the QSDW in the lower thermosphere. Summer time mesospheric planetary wave generation may be caused by barotropic and/or baroclinic instability due to strong jet stream as discussed before in the case of winter (Plumb, 1983). 
The QSDW is considered to have a mighty influence on the background mean flow and hence control the propagation of the other shorter period planetary waves, gravity waves, and tides. Using numerical study, Hagan et al. (1993) demonstrated that existence of a strong lower thermospheric jet in summer could act as a reflecting layer and consequent wave enhancement. Therefore enhanced long period planetary waves, e.g., QSDW etc. have a potential to modulate the propagating short period waves at the timescale of the periods of the longer ones. A recent study by Huang et al. (2013) reported strong interaction between the QSDW and tides (especially the diurnal tide). They also found clear signature of interaction between the newly generated secondary wave and QSDW. With long-term meteor wind observations over CP, Guharay et al. (2015a, b) found predominate coupling of the QSDW with diurnal tide and quasi-2-day wave (QTDW) and subsequent variability in the wave amplitudes. In the present study the results of bispectra clearly reveal appreciable coupling between the QSDW and shorter period planetary waves.

\section{Summary and conclusions}

The present work has depicted comparative study of the QSDW utilizing meteor wind observations from three Brazilian stations as well as ECMWF winds. The wave exhibited evident latitudinal variability with increasing amplitude with latitude. Both eastward and westward components of the QSDW are found to be prominent and strong activity in zonal wave number 1 is observed. The wave amplitude exhibits multiple peaks during various times of the year with largest one in summer in the MLT and the largest peak in the stratosphere is found in winter. The dominant wave components vary from the westward to eastward from the tropical to mid-latitude in the stratosphere. The bispectra reveals coupling of the QSDW with other short period planetary waves most probably through nonlinear interactions especially at $\mathrm{CA}$ and $\mathrm{CP}$.

Acknowledgements. The present work is supported by the Department of Space, Government of India and Conselho Nacional de Desenvolvimento Cientifico e Tecnologio, CNPq, Government of Brasil. The authors thank the European Center for the Medium-Range Weather Forecasts (ECMWF) for providing necessary data which are available at: http://apps.ecmwf.int/datasets/data/ interim-full-daily/. Thanks are due to R. Sekar and D. Chakrabarty for very useful discussions.

The topical editor, A. J. Kavanagh, thanks the two anonymous referees for help in evaluating this paper.

\section{References}

Charney, J. G. and Drazin, P. G.: Propagation of planetary-scale disturbances from lower into upper atmosphere, J. Geophys. Res., 66, 83-109, 1961.

Day, K. A. and Mitchell, N. J.: The 16-day wave in the Arctic and Antarctic mesosphere and lower thermosphere, Atmos. Chem. Phys., 10, 1461-1472, doi:10.5194/acp-10-1461-2010, 2010.

Day, K. A., Hibbins, R. E., and Mitchell, N. J.: Aura MLS observations of the westward-propagating $s=1$, 16-day planetary wave in the stratosphere, mesosphere and lower thermosphere, Atmos. Chem. Phys., 11, 4149-4161, doi:10.5194/acp-11-41492011, 2011.

Espy, P. J., Stegman, J., and Witt, G.: Interannual variations of the quasi-16-day oscillation in the polar summer mesospheric temperature, J. Geophys. Res., 102, 1983-1990, 1997.

Forbes, J. M., Hagan, M. E., Miyahara, S., Vial, F., Mason, A. H., Meek, C. E., and Portnyagin, Y. I.: Quasi 16-day oscillation in the mesosphere and lower thermosphere, J. Geophys. Res., 100, 9149-9163, 1995.

Guharay, A. and Sekar, R.: Signature of latitudinal coupling during a major sudden stratospheric warming in the tropics, J. Atmos. Sol.-Terr. Phy., 75, 122-126, doi:10.1016/j.jastp.2011.06.010, 2012.

Guharay, A., Batista, P. P., Clemesha, B. R., and Sarkhel, S.: Response of the extratropical middle atmosphere to the September 2002 major stratospheric sudden warming, Adv. Space Res., 53, 257-264, doi:10.1016/j.asr.2013.11.002, 2014.

Guharay, A., Batista, P. P., and Clemesha, B. R.: On the variability of the diurnal tideand coupling with planetary waves in the MLT over Cachoeira Paulista $\left(22.7^{\circ} \mathrm{S}, 45^{\circ} \mathrm{W}\right)$, J. Atmos. Sol.-Terr. Phy., 133, 7-17, doi:10.1016/j.jastp.2015.07.016, 2015a.

Guharay, A., Batista, P. P., and Clemesha, B. R.: Variability of the quasi-2-day wave and interaction with the longer period planetary waves in the MLT at Cachoeira Paulista (22.7 S, 45 $\left.{ }^{\circ} \mathrm{W}\right)$, J. Atmos. Sol.-Terr. Phy., 130-131, 57-67, doi:10.1016/j.jastp.2015.05.010, 2015b.

Hagan, M. E., Forbes, J. M., and Vial, F.: Numerical investigation of the propagation of the quasi-2-day wave into the lower thermosphere, J. Geophys. Res., 98, 23193-23205, 1993.

Hocking, W. K., Fuller, B., and Vandepeer, B.: Real-time determination of meteorrelated parameters utilizing modern digital technology, J. Atmos. Sol.-Terr. Phy., 63, 155-169, 2001.

Hoffmann, P., Singer, W., Keuer, D., Hocking, W. K., Kunzec, M., and Murayama, Y.: Latitudinal and longitudinal variability of mesospheric winds and temperatures during stratospheric warming events, J. Atmos. Sol.-Terr. Phy., 69, 2355-2366, 2007.

Huang, K. M., Liu, A. Z., Zhang, S. D., Yi, F., Huang, C. M., Gan, Q., Gong, Y., and Zhang, Y. H.: A nonlinear interaction event between a 16-day wave and a diurnal tide from meteor radar observations, Ann. Geophys., 31, 2039-2048, doi:10.5194/angeo31-2039-2013, 2013.

Jacobi, C., Schminder, R., and Kürschner, D.: Long-period (1225 days) oscillations in the summer mesopause region as measured at Collm $\left(52^{\circ} \mathrm{N}, 15^{\circ} \mathrm{E}\right)$ and their dependence on the equatorial quasi-biennial oscillation, Contrib. Atmos. Phys., 71, 461464, 1998.

Kim, Y. C. and Powers, E. J.: Digital bispectral analysis and its application to non-linear wave interactions, IEEE Trans. Plasma Sci., PS-7, 2, 120-131, 1979. 
Kingsley, S. P., Muller, H. G., Nelson, L., and Scholefield, A.: Meteor winds over Sheffield, J. Atmos. Sol.-Terr. Phy., 40, 917-922, 1978.

Lima, L. M., Batista, P. P., Clemasha, B. R., and Takahashi, H.: 16day wave observed in the meteor winds at low latitudes in the southern hemisphere, Adv. Space Res., 38, 2615-2620, 2006.

Lu, X., Chu, X., Fuller-Rowell, T., Chang, L., Fong, W., and Yu, Z.: Eastward propagating planetary waves with periods of 1-5 days in the winter Antarctic stratosphere as revealed by MERRA and lidar, J. Geophys. Res. Atmos., 118, 9565-9578, doi:10.1002/jgrd.50717, 2013.

Luo, Y., Manson, A. H., Meek, C. E., Meyer, C. K., Burrage, M. D., Fritts, D. C., Hall, C. M., Hocking, W. K., MacDougall, J., Riggin, D. M., and Vincent, R. A.: The 16-day planetary waves: multi-MF radar observations from the arctic to equator and comparisons with the HRDI measurements and the GSWM modelling results, Ann. Geophys., 20, 691-709, doi:10.5194/angeo20-691-2002, 2002.

Malinga, S. B. and Poole, L. M. G.: The 16-day variation in the mean flow at Grahamstown $\left(33.3^{\circ} \mathrm{S}, 26.5^{\circ} \mathrm{E}\right)$, Ann. Geophys., 20, 2027-2031, doi:10.5194/angeo-20-2027-2002, 2002..

McDonald, A. J., Hibbins, R. E., and Jarvis, M. J.: Properties of the quasi 16 day wave derived from EOS MLS observations, J. Geophys. Res., 116, D06112, doi:10.1029/2010JD014719, 2011. Mitchell, N. J., Middleton, H. R., Beard, A. G., Williams, P. J. S., and Muller, H. G.: The 16-day planetary wave in the mesosphere and lower thermosphere, Ann. Geophys., 17, 1447-1456, doi:10.1007/s00585-999-1447-9, 1999.
Plumb, R. A.: Baroclinic instability of the summer mesosphere-a mechanism for the quasi-2-daywave, J. Atmos.Sci., 40, 262-270, 1983.

Salby, M. L.: Rossby Normal Modes in Nonuniform Background Configurations. Part I: Simple fields, J. Atmos. Sci., 38, 1803 1826, 1981.

Shepherd, M. G. and Tsuda, T.: Large-scale planetary disturbances in stratospheric temperature at high-latitudes in the southern summer hemisphere, Atmos. Chem. Phys., 8, 7557-7570, doi:10.5194/acp-8-7557-2008, 2008.

Shiotani, M., Kuroi, K., and Hirota, I.: Eastward travelling waves in the Southern Hemisphere stratosphere during the spring of 1983, Q. J. Roy. Meteor. Soc., 116, 913-927, 1990.

Ushimaru, S. and Tanaka, H.: A numerical study of the interaction between stationary Rossby waves and eastward-traveling waves in the Southern Hemisphere stratosphere, J. Atmos. Sci., 49, 1354-1373, 1992.

Volland, H.: Atmospheric tidal and planetary waves, Kluwer Academic Publishers, 12, the Netherlands, doi:10.1007/978-94-0092861-9, 1988.

Williams, C. R. and Avery, S. K.: Analysis of long-period waves using the mesosphere-stratosphere-troposphere radar at Poker Flat, Alaska, J. Geophys. Res., 97, 20855-20861, 1992. 